\title{
CONSTRUCCIÓN DE LA IDENTIDAD PROFESIONAL EN LOS FUTUROS MAESTROS DE INFANTIL
}

Construction of professional identity in future teachers of Early Childhood Education

Construção da identidade profissional em futuros professores de Educação Infantil

\author{
Isabel Cantón Mayo (1) \\ Sheila García-Martín (2) \\ Ruth Cañón Rodríguez (3)
}

(1) Universidad de León, España. Teléfono: +34 987291029. Correo electrónico: icanm@unileon.es

(2) Universidad de León, España. Teléfono: +34 987295175. Correo electrónico: sgarcm@unileon.es

(3) Universidad de León, España. Teléfono: +34987295185. Correo electrónico: rcanr@unileon.es

\begin{abstract}
Resumen
La identidad profesional docente puede entenderse como el desarrollo gradual de las acciones profesionales que constituyen la especialidad de su oficio. En la actualidad, encontramos elementos que se mueven entre el desánimo y el orgullo profesional, pudiendo establecerse cuatro categorías: los desanimados, los satisfechos, los inquebrantables y los adaptados. Para conocer la identidad profesional de los futuros docentes de Educación Infantil, se diseñó y aplicó un cuestionario a 61 estudiantes del Prácticum II del Grado de Educación Infantil de la Universidad de León. Los resultados muestran que la mayoría está satisfecha con la profesión docente, pero insiste en la baja consideración social y en el esfuerzo que conlleva la tarea docente, con una carga de trabajo excesiva y un sueldo bajo.

Palabras claves: Identidad Profesional; Profesión Docente; Educación Infantil
\end{abstract}

\begin{abstract}
Professional teacher identity is understood as the gradual development of the professional actions that constitute the specialization of his trade. Nowadays, we find
\end{abstract}


elements that move between discouragement and professional pride, being able to establish four categories: the discouraged, the satisfied, the unshakeable and the adapted. In order to know the professional identity of the future teachers of Early Childhood Education, we designed and applied a questionnaire to 61 students of Practicum II of the Bachelor of Early Childhood Education of the University of León. The results showed that the majority of teachers are satisfied with teaching profession, but insists on the low social consideration and the effort involved in the teaching task, with an excessive workload and a low salary.

Keywords: Professional Identity; Teaching Profession; Early Childhood Education

\section{Resumo}

Identidade profissional dos profesores é entendida como o desenvolvimento gradual de ações profissionais que são a especialidade do seu ofício. Actualmente, encontramos elementos que se movem entre desânimo e orgulho profissional, sendo capaz de estabelecer quatro categorias: os desanimados, os satisfeito, os inquebrável e os adaptado. Para atender à identidade profissional dos futuros professores de Educação Infantil, foi concebido e aplicado um questionário em 61 alunos da Practicum II da Licenciatura em Educação Infantil da Universidade de León. Os resultados mostram que a maioria está satisfeita com a profissão docente, mas insiste o baixo status social eo esforço envolvido na tarefa de ensino com uma pesada carga de trabalho e baixos salários.

Palavras-chave: Identidade Profissional; Profissão docente; Educação Infantil

\section{Introducción}

La identidad profesional docente puede entenderse como el desarrollo gradual de las acciones profesionales que constituyen la especialidad de su oficio y es el mecanismo por el cual los docentes se reconocen y son reconocidos por otros como miembros de una determinada categoría social (Gysling, 1992; Prieto, 2004; Veiravé, Ojeda, Nuñez, \& Delgado, 2006). En época no muy lejana la identidad de los profesores era relativamente estable, al igual que lo eran las instituciones en las que realizaban su trabajo. Durante siglos los docentes han construido su identidad profesional basándose en su cualificación y su pertenencia a una determinada institución educativa. 
Respecto a la identidad actual de los docentes, Tardif (2004) indica que existen elementos que se mueven entre el desánimo (todos pueden enseñar y se sienten legitimados para atacar al profesor) y el orgullo profesional (estamos formando a las personas del mañana). Los docentes desanimados si pueden, abandonan la profesión, bien sea por insatisfacción individual, por la carga de trabajo, el salario o la baja consideración social; porque la profesión no satisface sus expectativas previas; o porque no ha sentido ni vocación ni atracción por ese trabajo. En el grupo de los que deciden optar por el orgullo profesional, tenemos a los satisfechos (estabilidad, tarea y medio), a los inquebrantables, no tan estables como los anteriores pero decididos a sobrevivir como docentes; y a los adaptados que, aunque no encuentren lo que esperaban en la profesión, ajustan sus expectativas a lo que hay. Si tenemos en cuenta que las competencias adquiridas en el Prácticum contribuyen tanto a la capacidad para enseñar como a la construcción de la identidad docente (Tejada \& Rui, 2013). ¿Cómo definen su identidad profesional los futuros docentes de Educación Infantil?

\section{Método}

El objetivo de este estudio fue conocer cómo los estudiantes del Grado de Educación Infantil definen la identidad profesional durante el Prácticum II. Se ha usado una metodología descriptivo-explicativa de orden cuantitativo y ex post facto. El instrumento utilizado fue un cuestionario con dos categorías: desánimo (insatisfechos, abandono de la profesión y emancipados de la docencia) y orgullo profesional (satisfechos, inquebrantables y adaptados) que se aplicó a 61 estudiantes. Posteriormente, los datos fueron analizados mediante el programa estadístico SPSS.

\section{Resultados y discusión}

La muestra estuvo formada por 57 mujeres y 3 hombres. De esos 61 estudiantes 30 tenían entre 19 y 22 años, 28 tenían entre 23 y 26 años y 3 entre 27 y 31 años. La mayoría eligió el grado de maestro como primera opción de estudios ( $\mathrm{N}=51)$ y accedieron a través del Bachillerato (70,5\%) o de la Formación Profesional (29,5\%).

En cuanto a su nivel general de satisfacción con la carrera estudiada, el 39,3\% está bastante satisfecho con los estudios realizados, seguido de un 37,7\% que por el contrario consideran sentirse poco satisfechos. Son los estudiantes más jóvenes los que muestran menor satisfacción, pues el 46\% de los alumnos de entre 19 y 22 años está poco o nada satisfecho con los estudios realizados. Mientras que son los estudiantes 
procedentes de Bachillerato los que muestran una mayor satisfacción con los estudios (60\%) que los procedentes de FP (50\%).

Relativo a la categoría de Desánimo, se evaluaron 26 ítems divididos en 3 subcategorías: Insatisfechos (11 ítems), Abandono de la profesión (9) y Emancipados de la docencia (6). Dichos ítems y sus porcentajes obtenidos se presentan en el siguiente gráfico (Figura 1).

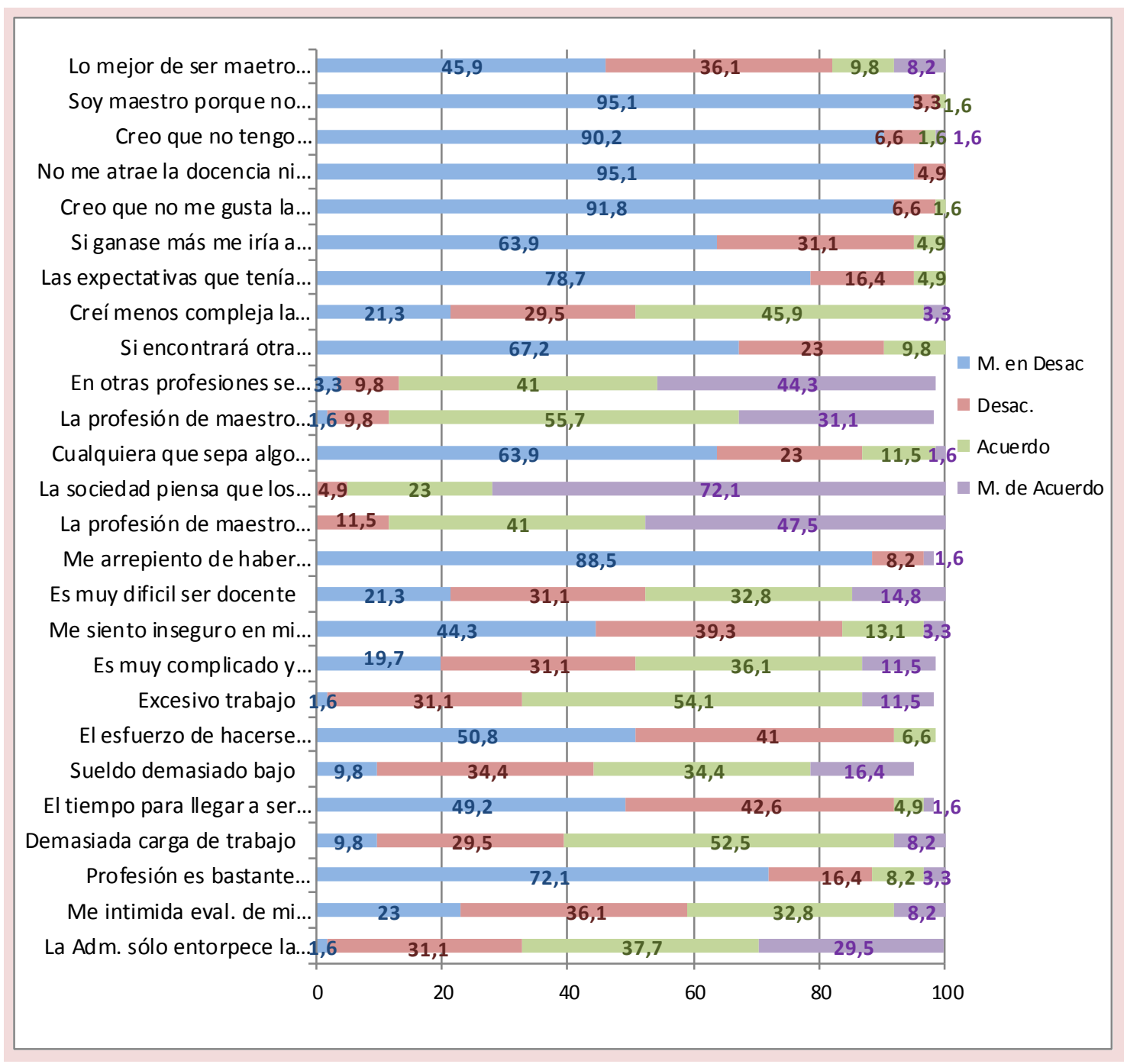

Figura 1.

Ítems de la categoría Desánimo y porcentajes obtenidos

La totalidad de la muestra afirma sentirse atraída por la docencia y sus cometidos profesionales, que les gusta la docencia $(98,4 \%)$ y que no han elegido esta profesión por no haber podido ser otra cosa $(98,4 \%)$ ya que sienten tener vocación de maestros (96,8\%). 
A pesar de ello, un 95,1\% destaca que la sociedad considera que los maestros trabajan poco, por lo que tienen baja consideración social (86,8\%) y que hay otras profesiones con las que se gana más con menos esfuerzo (85,5\%).

Respecto a la segunda de las categorías, dividida en tres subcategorías: satisfechos (11 ítems), inquebrantables (7 ítems) y adaptados (7 ítems), comprobamos en la Figura 2 que todos los encuestados se sienten a gusto con la profesión docente y que adoptarán los cambios necesarios para estar al día.

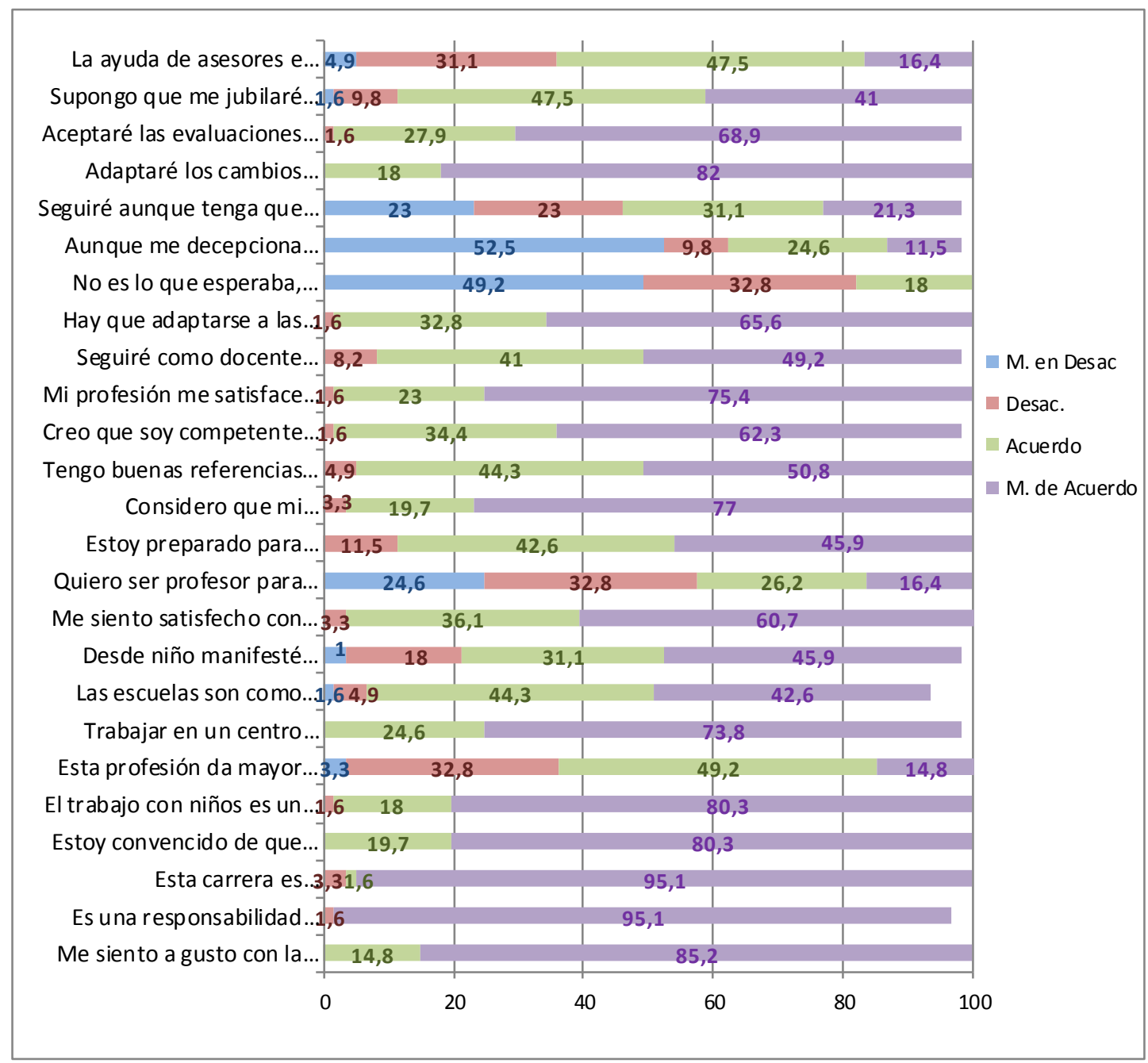

Figura 2.

Ítems de la categoría Orgullo profesional y porcentajes obtenidos

Un 98,3\% considera que trabajar con niños es un privilegio, que es lo que les gusta, que es una profesión que les satisface totalmente y que por lo tanto han de adaptarse a las necesidades que requiera. De igual modo, un 96,7\% considera que la docencia es una carrera apasionante, aunque quedan ámbitos por descubrir, que es una profesión con gran impacto social, que se sienten satisfechos con los resultados de su Construcción de la identidad profesional en los futuros maestros de infantil 
práctica docente y competentes como maestros. Consideran que es una responsabilidad formar a las generaciones futuras, pero que cuentan con buenas referencias sobre la profesión que van a ejercer (95,1\%).

\section{Conclusiones}

La mayoría de los futuros docentes de Educación Infantil muestran satisfacción con los estudios realizados, aunque los que se muestran más satisfechos son los alumnos con estudios previos de Bachillerato, así como los jóvenes de entre 23 y 26 años. La mayor parte de los encuestados muestra su convicción de continuar en la docencia a pesar de las bajadas de sueldo o de las evaluaciones a su trabajo. Sin embargo, sólo uno de cada dos docentes aceptaría replantearse su docencia. Además, insisten en una consideración social de la profesión y en un sueldo bajos, lo que ya constataron otros autores (González \& Subaldo, 2015). Como futuras líneas de investigación sería de interés conocer la opinión de los estudiantes de otras titulaciones de educación y así poder contrastar los resultados.

\section{Referencias}

González, J., \& Subaldo, L. (2015). Opiniones sobre el desempeño docente y sus repercusiones en la satisfacción profesional y personal de los profesores. Educación, 47(24), 90-114.

Gysling, J. (1992). Profesores: un análisis de su identidad social. CIDE. Santiago de Chile.

Prieto, M. (2004). La construcción de la identidad profesional del docente: Un desafío permanente. Enfoques Educacionales, 6(1), 29-49.

Tejada, J., \& Rui, C. (2013) Significación del Prácticum en la adquisición de competencias profesionales que permiten la transferencia de conocimiento a ámbitos propios de la acción docente. Revista de currículum y formación del profesorado, 3(17), 91-102.

Tardif, M. (2004). Los saberes del docente y su desarrollo profesional. Madrid: Narcea.

Veiravé, D., Ojeda, M., Núñez, C., \& Delgado, P. (2006). La construcción de la identidad de los profesores de enseñanza media. Biografías de profesores. Revista Iberoamericana de Educación, 40(3), 1-11. 